\title{
Acute changes of lung volumes and lung mechanics in asthma and in normal subjects
}

\author{
P. W. HOLMES, A. H. CAMPBELl, AND C. E. BARTER \\ From the Division of Thoracic Medicine, Repatriation General Hospital, Heidelberg, Australia 3077
}

\begin{abstract}
Holmes, P. W., Campbell, A. H., and Barter, C. E. (1978). Thorax, 33, 394-400. Acute changes of lung volumes and lung mechanics in asthma and in normal subjects. Lung volumes, pulmonary mechanics, and specific airway conductance (sGaw) were studied before and 15 minutes after $200 \mu \mathrm{g}$ of aerosol salbutamol in nine asthmatics undergoing mild spontaneous exacerbations of their disease and in five normal subjects. In addition, three of the normal subjects were studied after voluntarily breathing at high lung volumes for one minute.

The normal subjects and four of the asthmatics showed no overall changes in lung volumes or pressure-volume (PV) curves after salbutamol, even though airway dilatation was produced in the asthmatic subjects. In another five asthmatics, salbutamol induced a significant fall in the total lung capacity (TLC) in three, and in the residual volume and functional residual capacity in all five. There was a significant displacement of the PV curve downwards and to the right in all five, with increased lung compliance ( $\mathrm{Cl}$ stat) in two.

The fall in TLC could be accounted for by the increase in lung elasticity. There is reason to believe that this change in lung mechanics could be due to the reversal of asthma-induced stress relaxation.

Sustained breathing at high lung volume is known to cause stress relaxation of the lung. However, this breathing pattern did not alter the PV curve or TLC in two of three normal subjects, which is consistent with stress relaxation being rapidly reversible. The other normal subject had an acute shift of the PV curve upwards and to the left after breathing at high lung volume. It has been concluded that stress relaxation is usually rapidly reversed but that in some individuals it may only be slowly reversed. This more persistent form of stress relaxation may contribute to the acute changes of TLC found in some asthmatics.
\end{abstract}

Previous studies of lung volumes in asthma have shown that reversible increase in residual volume (RV), functional residual capacity (FRC), and total lung capacity (TLC) may occur (Woolcock and Read, 1966; Stanescu and Teculescu, 1970). Changes have also been found in the characteristics of the pressure volume (PV) curve, including a fall in lung elastic recoil pressure and a parallel shift of the PV curve upwards and to the left (Gold et al., 1967; Woolcock and Read, 1968). More recently, similar changes in lung volumes and mechanics have been demonstrated by provoking asthma with methacholine (Cade et al., 1971), histamine (Stanescu et al., 1973), or exercise (Anderson et al., 1972; Freedman et al., 1975; Peress et al., 1976). These induced acute changes could be reversed quickly with a bronchodilator
(Cade et al., 1971; Freedman et al., 1975). It응 would be expected that administration of aerosols salbutamol during a spontaneous asthmatic epi-․ㅡ. sode would have similar effects on lung elasticityñ with a fall in TLC. However, Colebatch et al. . $^{\circ}$ (1973) failed to demonstrate any change in mean 0 TLC or maximum lung elastic recoil (PI max after the administration of isoprenaline aerosol too a group of asthmatics. The mean PV curve waso not shifted as a whole to the right, although at lung volumes close to FRC it was displaced to the? right with an increased slope after broncho- $\square$ dilator. The apparent inconsistency of these re-웅 sults may be due to the type or severity of the asthma being studied, as most investigators found $\vec{\Phi}$ that the reversible changes in lung volumes andolung elasticity occurred only in some, not all, 
asthmatics. To attempt to unravel some of the underlying mechanisms and precipitating cause of the changes in lung volumes in asthma, we examined the responses to salbutamol aerosol of a group of asthmatics with spontaneous exacerbations of asthma of differing severity. In addition, an attempt was made to demonstrate whether acute changes in lung volumes and mechanics could be induced in normal subjects breathing at high lung volumes.

\section{Subjects}

Asthmatic subjects were asked to take part in the study if they had previously demonstrated an improvement in the forced expiratory volume in one second $\left(\mathrm{FEV}_{1.0}\right)$ of greater than $15 \%$ after $200 \mu \mathrm{g}$ of aerosol salbutamol, and if they were able to produce technically adequate thoracic gas volume (TGV) measurements in the presence of raised airway resistance (Raw). Seven men and two women fulfilled the selection criteria. They were aged between 30 and 64 years. The subjects were studied whilst experiencing mild asthma symptoms. They had not taken any sympathomimetic drugs for at least six hours before testing.

In addition to their asthma, two subjects ( 7 and 13) smoked five cigarettes daily and had chronic productive cough, and two ( 7 and 8 , an ex-smoker) had radiological changes consistent with emphysema. Two other asthmatics smoked 20 to 40 cigarettes daily ( 9 and 11). Five normal men aged between 30 and 59 years agreed to undergo the same procedures for the purposes of comparison. One of these smoked two cigars daily.

\section{Methods}

Vital capacity (VC) and $\mathrm{FEV}_{1 \cdot 0}$ were measured with a calibrated 8-litre Godart water-filled spirometer. The best of three closely reproducible measurements was accepted and corrected to BTPS.

Lung volumes and specific airway resistance (SRaw) were measured in a constant volume body plethysmograph. SRaw was derived from the boxpressure (BP) measured with a Furness MDC transducer and from air flow at the mouth measured with a Fleisch No. 3 pneumotachograph. Looping of the BP/flow trace due to temperature and humidity changes was corrected electronically by subtracting a signal proportional to the respired volume (Barter and Campbell, 1973). This enabled SRaw measurements to be made during quiet breathing. The measurements were made at the beginning of inspiration, at a flow of $0.51 / \mathrm{s}$. The BP/flow traces were displayed on a calibrated Tetronix cathode ray oscilloscope (CRO) type 564, and photographed. TGV was measured at zero flow with the patient panting against a closed mouth shutter. The difference between mouth and atmospheric pressure was measured with a Statham PMS pressure transducer. The $\mathrm{BP} /$ mouth pressure traces were also displayed on the oscilloscope and photographed, and the TGV was calculated. Simultaneous traces of tidal volume and occluded volume were displayed on an Offner multichannel recorder, allowing FRC to be measured. Inspiratory capacity manoeuvres immediately after the TGV measurements allowed the total lung capacity (TLC) to be determined.

An oesophageal balloon was passed so that the balloon tip was situated $45 \mathrm{~cm}$ from the anterior nares, and the balloon volume was maintained at $0.4 \mathrm{ml}$ of air. Mouth to oesophageal pressure was measured with a Statham PMG TC pressure transducer, and the trace was recorded on the Offner multichannel recorder together with the respired volume trace obtained by integration of the flow signal at the mouth. With the subject seated in the closed plethysmograph, the TGV was measured at FRC. An immediate inspiration to TLC was then made with simultaneous estimation of $\mathrm{Pl}$ max. A slow expiration followed during which static expiratory PV measurements were made in the standard manner.

In addition, static PV measurements were obtained in three of the normal subjects $(1,4$, and $5)$ immediately after breathing at high lung volumes for 45 to 60 seconds. On a separate occasion the static inspiratory and expiratory PV measurements were obtained in one of the normal subjects (4) before and after breathing at high lung volume. This allowed hysteresis of the PV curve to be examined.

All procedures other than spirometry were carried out at least five times initially, and they were repeated at least five times, beginning 15 minutes after two puffs $(200 \mu \mathrm{g})$ of salbutamol. Finally, post-bronchodilator values for $\mathrm{FEV}_{1 \cdot 0}$ and VC were obtained with the Godart spirometer.

Mean values of SRaw, FRC, TLC, Pl max, and static expiratory lung compliance ( $\mathrm{Cl}$ stat) were derived from at least five measurements of each. The TGV traces were placed in random order and measured by one of us (CEB) without knowledge of the order in which they had been obtained. Residual volume (RV) was obtained by subtracting VC from TLC. SRaw measurements were divided by FRC, and instrument resistance was subtracted, giving airway resistance (Raw). Specific airway 
conductance (sGaw) was measured as the reciprocal of Raw divided by FRC. Cl stat was derived from regression equations applied to the PV curves between FRC and 1 litre above FRC.

Measurements after salbutamol in each subject were compared with the pre-bronchodilator results, using the Wilcoxon rank test. The results from groups of patients before and after salbutamol were compared by means of the paired $t$ test.

\section{Results}

NORMAL SUBJECTS

The normal subjects (1-5) showed only slight changes in their mean lung volumes and pulmonary mechanics following salbutamol aerosol (Table 1). None of these changes was significant for the group, but when individual responses to salbutamol were examined, two subjects (2 and 4) had a significant increase in sGaw, one of these subjects (4) also having a significant improvement in $\mathrm{FEV}_{1.0}$ (Table 2). No significant changes were found in the elastic properties of the lungs after salbutamol.
Two of the three normals ( 1 and 5 ) studied after $\overrightarrow{\bar{N}}$ breathing at high lung volumes showed no changes in lung elasticity. The other normal subject (4), however, showed a reproducible shift of his PV curve upwards and to the left after breathing at a lung volume close to TLC for one minute (Fig. 1). This shift occurred to a lesser degree after salbutamol. The repeat study showed that hysteresis of the PV curves (Fig. 2) was not abolished or reduced when displaced to the left after high lung volume breathing.

\section{ASTHMATIC SUBJECTS}

As a group the asthmatic subjects (6-14) responded to salbutamol with significant increases in mean $\mathrm{FEV}_{1.0}$, sGaw, and $\mathrm{Cl}$ stat, significant reduction in FRC, $R V$, and $R V / T L C$ ratio, and no significant change in TLC or Pl max (Table 3).

Individual data show that the asthmatics did not respond uniformly to salbutamol. They can be divided into two groups according to whether or not there was a significant reduction in FRC after salbutamol. Thus group 1 subjects (6-9) had no change in FRC, and all group 2 subjects (10-14)

Table 1 Changes in lung function after aerosol salbutamol in five normal subjects

\begin{tabular}{|c|c|c|c|c|c|c|c|c|}
\hline & $\begin{array}{l}F E V_{1 \cdot 0} \\
\left(l s^{-1}\right)\end{array}$ & $\begin{array}{l}s G a w \\
\left.s^{-1} k P a^{-1}\right)\end{array}$ & $\begin{array}{l}R V \\
(l)\end{array}$ & $\begin{array}{l}R V / T L C \\
(\%)\end{array}$ & $\begin{array}{l}F R C \\
(l)\end{array}$ & $\begin{array}{l}T L C \\
(l)\end{array}$ & $\begin{array}{l}P l \max \\
(k P a)\end{array}$ & $\begin{array}{l}C l \text { stat } \\
\left(l k P a^{-1}\right)\end{array}$ \\
\hline Rest & $\begin{array}{c}4 \cdot 39 \\
(0 \cdot 37)\end{array}$ & $\begin{array}{c}1 \cdot 29 \\
(1 \cdot 02)\end{array}$ & $\begin{array}{c}2 \cdot 22 \\
(0 \cdot 56)\end{array}$ & $\begin{array}{l}28 \cdot 5 \\
(3 \cdot 8)\end{array}$ & $\begin{array}{c}4 \cdot 25 \\
(1 \cdot 04)\end{array}$ & $\begin{array}{c}7.68 \\
(0.91)\end{array}$ & $\begin{array}{c}2.85 \\
(0.47)\end{array}$ & $\begin{array}{c}2 \cdot 94 \\
(0 \cdot 61)\end{array}$ \\
\hline Post-salbutamol & $\begin{array}{c}4 \cdot 57 \\
(0 \cdot 50)\end{array}$ & $\begin{array}{r}1.47 \\
(0.91)\end{array}$ & $\begin{array}{c}2 \cdot 16 \\
(0 \cdot 47)\end{array}$ & $\begin{array}{l}28 \cdot 1 \\
(3 \cdot 5)\end{array}$ & $\begin{array}{c}4 \cdot 18 \\
(1 \cdot 03)\end{array}$ & $\begin{array}{c}7 \cdot 64 \\
(0 \cdot 80)\end{array}$ & $\begin{array}{c}2 \cdot 81 \\
(0 \cdot 60)\end{array}$ & $\begin{array}{c}2 \cdot 84 \\
(0 \cdot 75)\end{array}$ \\
\hline Mean $\%$ change & $4 \cdot 0$ & $13 \cdot 6$ & $-3 \cdot 3$ & $-1 \cdot 6$ & $-1 \cdot 4$ & -0.5 & $-1 \cdot 4$ & $-3 \cdot 4$ \\
\hline Significance* & NS & NS & NS & NS & NS & NS & NS & NS \\
\hline
\end{tabular}

One standard deviation in parentheses.

*Paired $t$ test.

Table 2 Mean percentage change in pulmonary function after aerosol salbutamol in five normal (1-5) and nine asthmatic (6-14) subjects

\begin{tabular}{|c|c|c|c|c|c|c|c|c|c|c|}
\hline Subject & $\begin{array}{l}\text { Age } \\
(y)\end{array}$ & $\begin{array}{l}\text { Height } \\
(\mathrm{cm})\end{array}$ & $F E V_{1 \cdot 0^{*}}$ & sGaw & $\boldsymbol{R} V^{*}$ & $R V / T L C^{*}$ & $F R C$ & $T L C$ & $P l \max$ & Cl stat \\
\hline $\begin{array}{l}1 \\
2 \\
3 \\
4 \\
5\end{array}$ & $\begin{array}{l}31 \\
36 \\
30 \\
59 \\
38\end{array}$ & $\begin{array}{l}180 \\
175 \\
178 \\
189 \\
173\end{array}$ & $\begin{array}{r}0.4 \\
2 \cdot 5 \\
-\quad 2 \cdot 1 \\
15 \cdot 1 \\
5.0\end{array}$ & $\begin{array}{l}-8 \cdot 7 \\
41 \cdot 2 \dagger \\
-3 \cdot 2 \\
98 \cdot 6 \dagger \\
0\end{array}$ & $\begin{aligned}-1 \cdot 9 \\
0 \\
8 \cdot 4 \\
-9 \cdot 3 \\
5 \cdot 0\end{aligned}$ & $\begin{array}{r}-16.1 \\
-\quad 3.9 \\
5.2 \\
-\quad 6.0 \\
3.6\end{array}$ & $\begin{array}{ll} & 0 \\
- & 0.8 \\
- & 5 \cdot 2 \\
- & 1.7 \\
1 \cdot 1\end{array}$ & $\begin{array}{r}0.7 \\
-\quad 1.7 \\
2.5 \\
-\quad 3.3 \\
1.1\end{array}$ & $\begin{array}{l}5 \cdot 7 \\
0 \\
6 \cdot 6 \\
-8 \cdot 5 \\
-\quad 5 \cdot 6\end{array}$ & $\begin{array}{r}-15 \cdot 4 \\
0 \\
-11 \cdot 1 \\
4 \cdot 0 \\
2 \cdot 5\end{array}$ \\
\hline $\begin{array}{l}6 \ddagger \\
7 \\
8 \\
9\end{array}$ & $\begin{array}{l}34 \\
49 \\
64 \\
59\end{array}$ & $\begin{array}{l}162 \\
166 \\
163 \\
168\end{array}$ & $\begin{array}{l}19 \cdot 2 \\
21 \cdot 1 \\
16 \cdot 6 \\
18 \cdot 2\end{array}$ & $\begin{array}{l}40 \cdot 6 \dagger \\
62 \cdot 6 \dagger \\
73 \cdot 3 \\
53 \cdot 5 \dagger\end{array}$ & $\begin{array}{r}-14 \cdot 1 \\
-1 \cdot 3 \\
1 \cdot 1 \\
-2 \cdot 8\end{array}$ & $\begin{array}{l}-7.9 \\
-3.5 \\
-2.5 \\
-1.8\end{array}$ & $\begin{array}{r}2.4 \\
0.3 \\
-0.7 \\
0.4\end{array}$ & $\begin{array}{c}-6.2 \dagger \\
0.7 \\
3.6 \\
-\quad 0.9\end{array}$ & $\begin{array}{c}-41.9 \dagger \\
5.1 \\
-4.0 \\
-6.7\end{array}$ & $\begin{array}{l}6 \cdot 0 \\
45 \cdot 7 \dagger \\
28 \cdot 1 \\
33 \cdot 6\end{array}$ \\
\hline $\begin{array}{l}10 \\
11 \\
12 \ddagger \\
13 \\
14\end{array}$ & $\begin{array}{l}60 \\
54 \\
47 \\
55 \\
56\end{array}$ & $\begin{array}{l}165 \\
183 \\
165 \\
170 \\
166\end{array}$ & $\begin{array}{r}150 \cdot 2 \\
75 \cdot 1 \\
50 \cdot 0 \\
15 \cdot 5 \\
145 \cdot 5\end{array}$ & $\begin{array}{r}312 \cdot 5 \dagger \\
69 \cdot 4 \dagger \\
142 \cdot 8 \dagger \\
114 \cdot 7 \dagger \\
113 \cdot 8 \dagger\end{array}$ & $\begin{array}{l}-31 \cdot 2 \\
-37 \cdot 7 \\
-25 \cdot 7 \\
-57 \cdot 9 \\
-41 \cdot 8\end{array}$ & $\begin{array}{r}-30.9 \\
-36.9 \\
-15 \cdot 1 \\
-52.8 \\
-34.4\end{array}$ & $\begin{array}{l}-16 \cdot 2 \dagger \\
-16 \cdot 6 \dagger \\
-21 \cdot 2 \dagger \\
-18 \cdot 3 \dagger \\
-11 \cdot 7 \dagger\end{array}$ & $\begin{array}{l}-1.8 \\
-1.3 \\
-12.6 \dagger \\
-11.8 \dagger \\
-6.1 \dagger\end{array}$ & $\begin{array}{r}18 \cdot 3 \dagger \\
31 \cdot 3 \dagger \\
13 \cdot 5 \\
3 \cdot 3 \\
-10.4\end{array}$ & $\begin{array}{c}9 \cdot 0 \\
34 \cdot 7 \\
104 \cdot 9 \dagger \\
64 \cdot 1 \dagger \\
12 \cdot 8\end{array}$ \\
\hline
\end{tabular}

*Insufficient number of separate measurements for statistical analysis.

†Statistically significant.

†Female patients. 


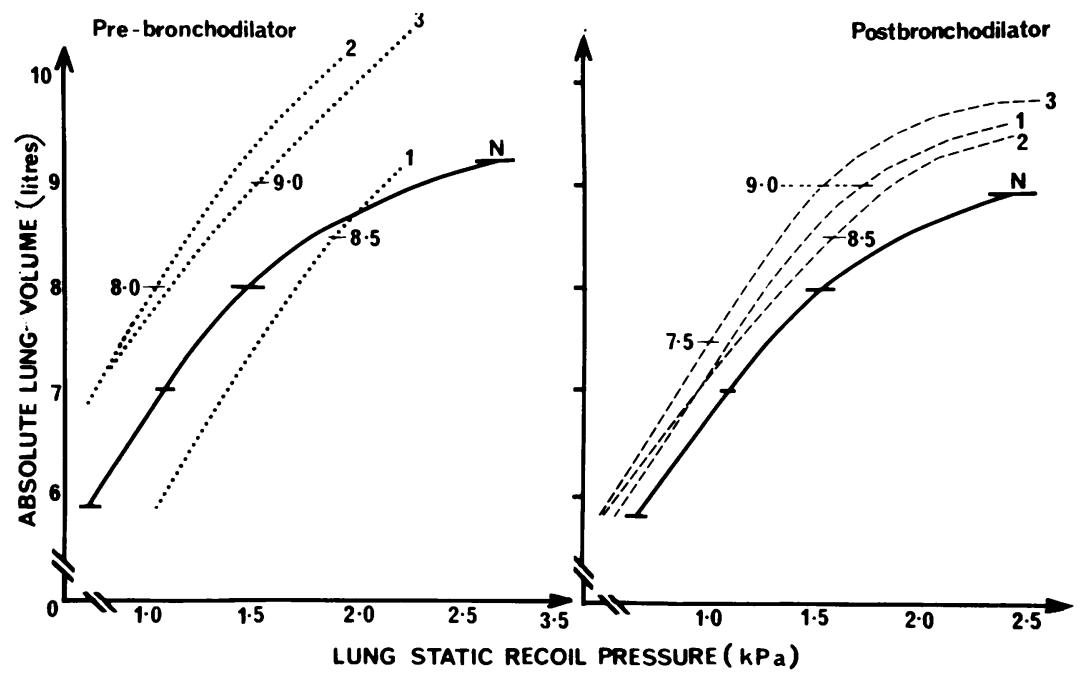

Fig. 1 Static expiratory pressure-volume (PV) curves of one normal subject before and after aerosol salbutamol. The mean of five PV curves $(N)$ obtained after normal breathing is compared with PV curves (1-3), each of which has been obtained after breathing for 60 seconds at the lung volumes indicated. The number refers to the serial order of the tests.

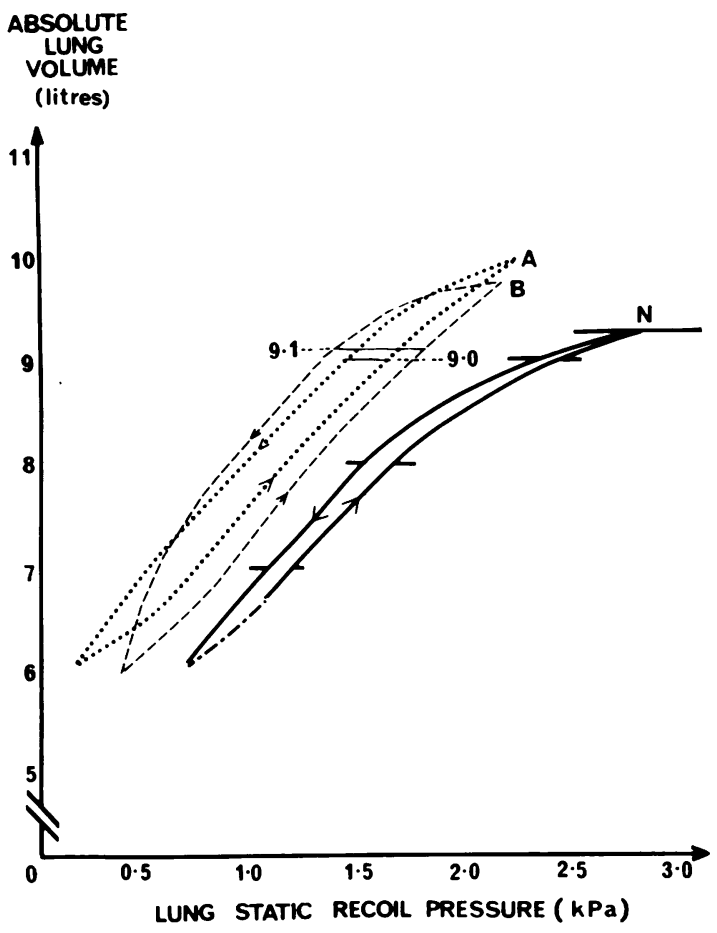

Fig. 2 Static inspiratory and expiratory $P V$ curves of one normal subject. The mean of five PV loops $(N)$ obtained after normal breathing is compared with two loops $(A$ and $B)$, each obtained after breathing for 60 seconds at the lung volumes indicated. had a significant fall in FRC after salbutamol. It was noted, however, that the two groups were not entirely similar in that before bronchodilator the overall degree of airway obstruction was less severe in group 1, which also contained the two subjects with radiological emphysema as well as asthma.

\section{Group 1}

The four group 1 asthmatics resembled the normals in having no change in mean lung volumes or mean lung compliance after salbutamol (Table 4). The members of this group had increases of greater than $15 \%$ in $\mathrm{FEV}_{1.0}$, with a mean percentage improvement of $54.1 \%$ in sGaw. There was a small but significant fall in RV/TLC in the group. None had an overall shift of the PV curve. One subject (7) had a significant increase in $\mathrm{Cl}$ stat after salbutamol. The PV curve of another subject (6) showed a reduced TLC and Pl max after salbutamol consistent with a lessened inspiratory effort.

\section{Group 2}

The five group 2 asthmatics showed significant mean changes in lung volumes and compliance after salbutamol (Table 4). There was a mean fall of $17 \%$ in FRC, the $\mathrm{FEV}_{1.0}$ and sGaw increasing by $73.9 \%$ and $128 \%$ respectively after salbutamol. The PV curves had become more convex with displacement downwards and to the right. Thus at any specified lung volume the elastic 
Table 3 Changes in lung function after aerosol salbutamol in nine asthmatic subjects

\begin{tabular}{|c|c|c|c|c|c|c|c|c|}
\hline & $\begin{array}{l}F E V_{1 \cdot 0} \\
(l)\end{array}$ & $\begin{array}{l}s G a w \\
\left(s^{-1} k P a^{-1}\right)\end{array}$ & $\begin{array}{l}R V \\
(I)\end{array}$ & $\begin{array}{l}R V / T L C \\
(\%)\end{array}$ & $\begin{array}{l}F R C \\
(l)\end{array}$ & $\begin{array}{l}T L C \\
(l)\end{array}$ & $\begin{array}{l}P \operatorname{lmax} \\
(k P a)\end{array}$ & $\begin{array}{l}\text { Clstat } \\
\left(l k \mathrm{~Pa}^{-1}\right)\end{array}$ \\
\hline Rest & $\begin{array}{c}1 \cdot 64 \\
(0.55)\end{array}$ & $\begin{array}{c}0.42 \\
(0.15)\end{array}$ & $\begin{array}{c}4 \cdot 1 \\
(1 \cdot 4)\end{array}$ & $\begin{array}{c}57 \cdot 0 \\
(12 \cdot 8)\end{array}$ & $\begin{array}{c}4 \cdot 96 \\
(1 \cdot 15)\end{array}$ & $\begin{array}{c}7 \cdot 03 \\
(1 \cdot 26)\end{array}$ & $\begin{array}{c}1 \cdot 52 \\
(0 \cdot 46)\end{array}$ & $\begin{array}{c}2 \cdot 84 \\
(1 \cdot 12)\end{array}$ \\
\hline Post-salbutamol & $\begin{array}{c}2 \cdot 38 \\
(0.48)\end{array}$ & $\begin{array}{c}0.78 \\
(0.22)\end{array}$ & $\begin{array}{c}3 \cdot 2 \\
(1 \cdot 3)\end{array}$ & $\begin{array}{c}45 \cdot 6 \\
(13 \cdot 3)\end{array}$ & $\begin{array}{c}4 \cdot 51 \\
(1 \cdot 21)\end{array}$ & $\begin{array}{c}6 \cdot 78 \\
(1 \cdot 45)\end{array}$ & $\begin{array}{c}1 \cdot 50 \\
(0.53)\end{array}$ & $\begin{array}{c}3 \cdot 82 \\
(1 \cdot 23)\end{array}$ \\
\hline Mean $\%$ change & $45 \cdot 1$ & $89 \cdot 4$ & $-21 \cdot 5$ & $-20 \cdot 1$ & $-9 \cdot 2$ & $-3 \cdot 5$ & -0.6 & $34 \cdot 4$ \\
\hline Significance* & $P<0.005$ & $P<0.01$ & $P<0.02$ & $P<0.01$ & $P<0.02$ & NS & NS & $P<0.01$ \\
\hline
\end{tabular}

One standard deviation in parenthesis.

* Paired $t$ test.

Table 4 Changes in lung function after aerosol salbutamol in nine asthnatics divided into two groups according to change in FRC

\begin{tabular}{|c|c|c|c|c|c|c|c|c|c|}
\hline & & $\begin{array}{l}F R C \\
(l)\end{array}$ & $\begin{array}{l}F E V_{1 \cdot 0} \\
(l)\end{array}$ & $\begin{array}{l}s G a w \\
\left(s^{-1} k P a^{-1}\right)\end{array}$ & $\begin{array}{l}R V \\
(l)\end{array}$ & $\begin{array}{l}R V / T L C \\
(\%)\end{array}$ & $\begin{array}{l}T L C \\
(l)\end{array}$ & $\begin{array}{l}P l \max \\
(k P a)\end{array}$ & $\begin{array}{l}\text { Cl stat } \\
\left(l k P a^{-1}\right)\end{array}$ \\
\hline $\begin{array}{l}\text { Group } 1 \\
\text { Asthmatics (6-9) }\end{array}$ & Rest & $\begin{array}{c}5 \cdot 17 \\
(1 \cdot 13)\end{array}$ & $\begin{array}{c}1.98 \\
(0.59)\end{array}$ & $\begin{array}{c}0.49 \\
(0 \cdot 10)\end{array}$ & $\begin{array}{c}4 \cdot 0 \\
(1 \cdot 2)\end{array}$ & $\begin{array}{l}54 \cdot 7 \\
(7 \cdot 7)\end{array}$ & $\begin{array}{c}7 \cdot 26 \\
(1 \cdot 29)\end{array}$ & $\begin{array}{c}1 \cdot 38 \\
(0 \cdot 41)\end{array}$ & $\begin{array}{c}3 \cdot 68 \\
(1 \cdot 31)\end{array}$ \\
\hline \multirow[t]{3}{*}{$\begin{array}{l}\text { No change } \\
\text { in FRC }\end{array}$} & Post-salbutamol & $\begin{array}{c}5 \cdot 14 \\
(1 \cdot 17)\end{array}$ & $\begin{array}{c}2 \cdot 35 \\
(0 \cdot 71)\end{array}$ & $\begin{array}{c}0.75 \\
(0 \cdot 10)\end{array}$ & $\begin{array}{c}3 \cdot 9 \\
(1 \cdot 3)\end{array}$ & $\begin{array}{l}52 \cdot 7 \\
(8 \cdot 5)\end{array}$ & $\begin{array}{c}7 \cdot 22 \\
(1 \cdot 38)\end{array}$ & $\begin{array}{l}1 \cdot 16 \\
(0 \cdot 14)\end{array}$ & $\begin{array}{c}4 \cdot 38 \\
(1.66)\end{array}$ \\
\hline & Mean $\%$ change & 0 & $19 \cdot 0$ & $54 \cdot 1$ & $-3 \cdot 3$ & $-3 \cdot 7$ & 0 & $-16 \cdot 2$ & $19 \cdot 0$ \\
\hline & Significance* & NS & $\mathrm{P}<0.01$ & $P<0.005$ & NS & $P<0.05$ & NS & NS & NS \\
\hline $\begin{array}{l}\text { Group } 2 \\
\text { Asthmatics (10-14) }\end{array}$ & Rest & $\begin{array}{c}4 \cdot 81 \\
(1 \cdot 29)\end{array}$ & $\begin{array}{r}1 \cdot 38 \\
(0 \cdot 38\end{array}$ & $\begin{array}{r}0.35 \\
(0.16)\end{array}$ & $\begin{array}{c}4 \cdot 2 \\
(1 \cdot 8)\end{array}$ & $\begin{array}{c}58 \cdot 8 \\
(16 \cdot 5)\end{array}$ & $\begin{array}{c}6 \cdot 85 \\
(1 \cdot 36)\end{array}$ & $\begin{array}{c}1 \cdot 62 \\
(0 \cdot 52)\end{array}$ & $\begin{array}{c}2 \cdot 18 \\
(0 \cdot 51)\end{array}$ \\
\hline \multirow[t]{3}{*}{$\begin{array}{l}\text { Significant fall } \\
\text { in FRC }\end{array}$} & Post-salbutamol & $\begin{array}{c}4 \cdot 00 \\
(1 \cdot 10)\end{array}$ & $\begin{array}{c}2 \cdot 40 \\
(0 \cdot 28)\end{array}$ & $\begin{array}{c}0.81 \\
(0.29)\end{array}$ & $\begin{array}{c}2 \cdot 7 \\
(1 \cdot 3)\end{array}$ & $\begin{array}{c}39.9 \\
(14 \cdot 4)\end{array}$ & $\begin{array}{c}6.44 \\
(1 \cdot 57)\end{array}$ & $\begin{array}{c}1 \cdot 78 \\
(0 \cdot 58)\end{array}$ & $\begin{array}{c}3 \cdot 38 \\
(0.66)\end{array}$ \\
\hline & Mean $\%$ change & $-16 \cdot 7$ & $73 \cdot 9$ & $128 \cdot 8$ & $-35 \cdot 5$ & $-32 \cdot 2$ & -6.0 & $10 \cdot 1$ & $55 \cdot 0$ \\
\hline & Significance* & $P<0.005$ & $P<0.01$ & $P<0.005$ & $P<0.005$ & $P<0.005$ & $P<0.05$ & NS & NS \\
\hline
\end{tabular}

One standard deviation in parentheses.

*Paired $t$ test.

recoil pressure was greater after salbutamol than before. This lung elasticity change would favour a reduced TLC which was seen to fall in all five cases, reaching statistical significance in three subjects (12-14). In the other two subjects (10 and 11) the Pl max rose significantly. In all the group 2 subjects there was an increase in static lung compliance after salbutamol both in the tidal ranges and at post-bronchodilator lung volumes matched with the pre-bronchodilator FRC. This increase reached statistical significance for the tidal range in only two subjects (12 and 13).

\section{Discussion}

Various changes of TLC and PV curves were found in this study. Firstly, some of our asthmatics resembled the normal controls in that lung volumes and lung elasticity were unchanged after a bronchodilator. Secondly, as observed by Colebatch et al. (1973), in one of our patients the lower end of the PV curve altered without an accompanying change of TLC. The reduced slope of the lower end of the PV curve before broncho응 dilator is attributable to closure of airways at low lung volumes (Finucane and Colebatch, 1969)을 This would be reversed as asthma improved afte a bronchodilator. Furthermore, closure of narrowed airways during expiration, with resultant trapping of gas in distal lung units, would also produce a shift to the left of the lower end of the PV curve, opposite changes occurring after bronchodilator.

The third pattern was of an acute change of TLC, accompanied by an acute shift of the entire PV curve, with or without a change in the slopes of the lower end of the curve. Change in the TLE only occurred when there was a shift of the entire PV curve, with the exception of subject 6 , i whom the decreased TLC was caused by a reduced inspiratory effort. These changes of lung elasticity can occur acutely within a few minute when asthma is induced or reversed (Stanescu eP al., 1973; Freedman et al., 1975).

It is noteworthy that all studies, including ours? show that some but not all asthmatics displas 
these changes of lung elasticity and TLC. Freedman et al. (1975) could find no other features enabling them to distinguish the patients who increased their TLC from those who did not. Evidently an exacerbation of asthma induces changes of TLC and the PV curve in those asthmatics who are susceptible to such changes.

The nature of this susceptibility is obscure. As has been discussed already, there is evidence that airway closure with air trapping may account for the reduced slope of the static deflation PV curve of the lung in asthma. However, changes of the lower end of the PV curve were not closely associated with change in TLC. Furthermore, it is unlikely that airway closure with air trapping can explain all the observed reduction of elastic retraction and increase of the TLC. This mechanism can account for only a small increase of TLC unless there is also reduced elastic recoil (Finucane and Colebatch, 1969).

Another possibility is that lung elasticity is changed by stress relaxation (Marshall and Widdicombe, 1960). While breath-holding at high lung volumes usually results in some degree of stress relaxation, this is often quickly reversed during breathholding at lower lung volumes. Thus Finucane and Colebatch (1969) found that after stress relaxation had been induced in normal subjects by full lung inflation for 50-60 seconds, the PV curves obtained during subsequent deflation showed no shift to the left. Similarly, two of our three normal subjects showed no shift of PV curves after breathing at a high lung volume for 45-60 seconds. Nevertheless, there was a shift of the PV curve to the left and an increase of TLC in one of our normal subjects after breathing at high lung volumes. This observation was reproducible, showing that stress relaxation (in its broadest sense) was reversed only slowly in this individual. If slow reversal of stress relaxation occurs in only some individuals, it may be the explanation for the fact that changes in lung elasticity and TLC are observed in some, but not all, asthmatics. This theory assumes that, in asthma, airway obstruction with inflation of the lungs can produce a similar sort of persisting stress relaxation. Whether some asthmatics do display persistence of stress relaxation has yet to be examined.

Changes of lung elasticity, more prolonged than the usual forms of stress relaxation, can be induced in animals by increasing the end-expiratory pressure of isolated lungs (Faridy et al., 1966; Raimondi et al., 1971) or by artificial airway obstruction (Buhain et al., 1972). These changes in elastic properties appear to have been caused by changes in surface forces. Distension of the lung leads to a reduction of surface tension from accumulation of surfactant within the alveoli (Faridy, 1976). Our normal subject with a shift of the PV curve after breathing at high lung volume displayed persisting hysteresis of the PV curve. Peress et al. (1976) also found that hysteresis of the PV curve persisted in an asthmatic subject when an acute shift of the PV curve had taken place during an acute attack. Hysteresis is attributed largely to surface forces, so its persistence suggests that surface tension is not reduced. However, surfactant itself displays hysteresis, so reduction of surface tension by an increase of surfactant could lead to displacement of the PV curve without abolition of the hysteresis.

Although the changes in elasticity of the lungs accounted for changes in TLC in our patients, alterations of chest wall compliance and muscle effort may be important in some other cases (Peress et al., 1976).

\section{References}

Anderson, S. D., McEvoy, J. D. S., and Bianco, S. (1972). Changes in lung volumes and airway resistance after exercise in asthmatic subjects. American Review of Respiratory Disease, 106, 30-37.

Barter, C. E., and Campbell, A. H. (1973). Comparison of airways resistance measurements during panting and quiet breathing. Respiration, 30, 1-11.

Buhain, W. J., Brody, J. S., and Fisher, A. B. (1972). Effect of artificial airway obstruction on elastic properties of the lung. Journal of Applied Physiology, 33, 589-594.

Cade, J. F., Woolcock, A. J., Rebuck, A. S., and Pain, M. C. F. (1971). Lung mechanics during provocation of asthma. Clinical Science, 40, 381-391.

Colebatch, H. J. H., Finucane, K. E., and Smith, M. M. (1973). Pulmonary conductance and elastic recoil relationships in asthma and emphysema. Journal of Applied Physiology, 34, 143-153.

Faridy, E. E., Permutt, S., and Riley, R. L. (1966). Effect of ventilation on surface forces in excised dogs' lungs. Journal of Applied Physiology, 21, 1453-1462.

Faridy, E. E. (1976). Effect of distension on release of surfactant in excised dogs' lungs. Respiration Physiology, 27, 99-114.

Finucane, K. E., and Colebatch, H. J. H. (1969). Elastic behavior of the lung in patients with airway obstruction. Journal of Applied Physiology, 26, 330-338.

Freedman, S., Tattersfield, A. E., and Pride, N. B. (1975). Changes in lung mechanics during asthma induced by exercise. Journal of Applied Physiology, 38, 974-982.

Gold, W. M., Kaufman, H. S., and Nadel, J. A. (1967). Elastic recoil of the lungs in chronic asthmatic 
patients before and after therapy. Journal of Applied Physiology, 23, 433-438.

Marshall, R., and Widdicombe, J. G. (1960). Stress relaxation of the human lung. Clinical Science, 20 , 19-31.

Peress, L., Sybrecht, G., and Macklem, P. T. (1976). The mechanism of increase in total lung capacity during acute asthma. American Journal of Medicine, 61, 165-169.

Raimondi, A. C., Massarella, G. R., and Pride, N. B. (1971). The effects of ventilation on the elastic recoil of excised dogs' lungs. Respiration Physiology, 12, 205-217.

Stanescu, D. C., Frans, A., and Brasseur, L. (1973). Acute increase in total lung capacity in asthma following histamine aerosols. Bulletin de Physio $\stackrel{\vec{F}}{\vec{P}}$ Pathologie Respiratoire, 9, 523-530.

Stanescu, D. C., and Teculescu, D. (1970). Pulmonares function in status asthmaticus: effect of therapye Thorax, 25, 581-586.

Woolcock, A. J., and Read, J. (1966). Lung volume尺 in exacerbations of asthma. American Journal o\% Medicine, 41, 259-273.

Woolcock, A. J., and Read, J. (1968). The static elastic properties of the lungs in asthma. American Review of Respiratory Disease, 98, 788-794.

Requests for reprints to: Dr. A. H. Campbell, Re patriation General Hospital, Heidelberg, Victoriał Australia, 3077. 